\title{
Discriminative Stimulus Effects of Pentobarbital in Pigeons
}

\author{
Seymore Herling, Rita J. Valentino, and Gail D. Winger \\ Departments of Pharmacology and Psychology, University of Michigan, Ann Arbor, Michigan 48109, USA
}

\begin{abstract}
Pigeons were trained to discriminate the IM injection of pentobarbital ( 5 or $10 \mathrm{mg} / \mathrm{kg}$ ) from saline in a task in which 20 consecutive pecks on one of two response keys produced access to mixed grain. Pentobarbital $(1.0-17.8 \mathrm{mg} / \mathrm{kg})$ produced a doserelated increase in the percentage of the total session responses that occurred on the pentobarbital-appropriate key. The concomitant administration of bemegride $(5.6-17.8 \mathrm{mg} / \mathrm{kg}$ ) antagonized the discriminative control of behavior exerted by the training dose of pentobarbital. Benzodiazepines, diazepam $(1.0 \mathrm{mg} /$ $\mathrm{kg})$ and clobazam $(3.2 \mathrm{mg} / \mathrm{kg})$, and barbiturates, methohexital $(10 \mathrm{mg} / \mathrm{kg})$, phenobarbital $(56 \mathrm{mg} / \mathrm{kg})$, and barbital $(56 \mathrm{mg} / \mathrm{kg})$, produced responding on the pentobarbital-appropriate key similar to that produced by pentobarbital. In contrast, narcotics such as morphine, ethylketazocine, cyclazocine, and SKF-10,047, at doses up to and including those that markedly suppressed response rates, produced responding predominantly on the saline-appropriate key. Similarly, the anticonvulsants, valproate, phenytoin, and ethosuximide occasioned only saline-appropriate behavior, indicating that not all anticonvulsants share discriminative stimulus effects with pentobarbital. Muscimol, a direct GABA agonist, and baclofen, a structural analogue of GABA, also failed to produce pentobarbital-appropriate responding. Ketamine, dextrorphan, and ethanol $(0.3-3.2 \mathrm{~g} / \mathrm{kg}$, orally) produced intermediate levels of pentobarbital-appropriate responding, suggesting that the discriminative effects of these drugs may be somewhat like those of pentobarbital.
\end{abstract}

Key words: Pentobarbital - Drug discrimination Pigeons

The discriminative stimulus properties of pentobarbital have been studied extensively in rodents (e.g., Overton

Offprint requests to: $S$. Herling
1966; Barry 1974; Krimmer 1974; Johansson and Jarbe 1975; Jarbe 1976) and to a lesser degree in primates (e.g., Trost and Ferraro 1974) and pigeons (e.g., Leberer and Fowler 1977; Witkin et al. 1980; Jarbe and Ohlin 1979). In rodents, a variety of drugs including amobarbital, barbital, diazepam, chlordiazepoxide, meprobamate, and chloral hydrate, have been shown to share discriminative effects with pentobarbital under a variety of different training and testing conditions (e.g., Barry 1974; Jarbe 1976; Colpaert et al. 1976). Although differences have been demonstrated in the discriminative effects of some of these compounds (e.g., chlordiazepoxide and pentobarbital: Overton 1966; Barry and Krimmer 1977; Krimmer and Barry 1979), some drugs are virtually indistinguishable from each other (e.g., pentobarbital and phenobarbital: Overton 1977). Likewise, under certain circumstances, ethanol and pentobarbital have discriminative effects which are sufficiently similar that each drug substitutes for the other (e.g., Overton 1966, 1977), although there are conditions that result in differences in discriminative effects between these two drugs (e.g., Barry and Krimmer 1972, 1977; Overton 1977).

Although discriminative stimulus effects for pentobarbital have previously been demonstrated in the pigeon (e.g., Leberer and Fowler 1977; Witkin et al. 1980; Jarbe and Ohlin 1979), an extensive characterization of its properties, such as that determined in rodents, has yet to be established in this species. Among narcotics, the spectrum of drug generalization has recently been shown to differ quite markedly among species (Woods et al. 1979; Hein et al. 1980). For example, while morphine and the kappa receptor agonists ketazocine and ethylketazocine (see Martin et al. 1976; Gilbert and Martin 1976) produce markedly different discriminative effects in both rodents and primates, the discriminative stimulus properties of these drugs in pigeons are strikingly similar (cf. Holtzman et al. 1977; Schaefer and Holtzman 1978; Woods et al. 1979; Herling et al. 1980a). The purpose of the present study was to characterize the discrimi- 
native stimulus properties of pentobarbital in the pigeon by evaluating the extent to which a variety of compounds produced discriminative effects similar to those of pentobarbital. Secondly, since the CNS stimulant bemegride has been shown to be an effective antagonist of the discriminative effects of pentobarbital in rats (e.g., Krimmer et al. 1978) and gerbils (e.g., Johansson and Jarbe 1975), it was of interest to determine the interaction between pentobarbital and bemegride in a non-mammalian species. Thirdly, the relationship of anticonvulsant activity to the discriminative stimulus effect of pentobarbital was assessed by evaluating the extent to which a number of nonbarbiturate anticonvulsants produced discriminative effects similar to those of pentobarbital. Finally, the involvement of the inhibitory neurotransmitter gamma-aminobutyric acid (GABA) in the discriminative effect produced by pentobarbital and drugs that share the pentobarbital discriminative effect (e.g., benzodiazepines) was studied by determining the degree of generalization to pentobarbital produced by muscimol, a direct GABA agonist, and baclofen, a structural analogue of GABA.

\section{Materials and Methods}

Subjects. The subjects were seven White Carneaux pigeons maintained at approximately $80 \%(450-500 \mathrm{~g})$ of their free-feeding weights. Sufficient mixed grain and Purina Pigeon Checkers were provided supplemental to the mixed grain earned during the experimental sessions to maintain these reduced weights. In addition, water and grit were freely provided in each animal's home cage.

Four of these pigeons had participated in an experiment that attempted to train a discrimination between $5 \mathrm{mg} / \mathrm{kg}$ pentobarbitai and saline under a two-key concurrent chain fixed-interval 5 min, fixed-ratio 20 response schedule of food presentation (Ferster and Skinner 1957). After approximately 4 months, during which time no detectable progress was made in establishing the drug-saline discrimination, these animals were trained under the simple fixed-ratio schedule described below. Three remaining pigeons were experimentally and drug naive prior to discrimination training. These pigeons showed no appreciable differences in either the acquisition or the maintenance of the drug discrimination as compared to the four experienced birds.

Apparatus. Experimental sessions were conducted in chambers essentially as described by Ferster and Skinner (1957). The experimental space of each chamber was approximately $36 \mathrm{~cm}$ high $\times 28 \mathrm{~cm}$ wide $\times 33 \mathrm{~cm}$ long. The inside front panel of each chamber contained two translucent response keys ( $2 \mathrm{~cm}$ diameter), located about $25 \mathrm{~cm}$ above the floor of the chamber and $5 \mathrm{~cm}$ apart, which were transilluminated during the experimental sessions by red $7 \mathrm{~W}$ lights located behind the keys. A larger transilluminated white disc $3.5 \mathrm{~cm}$ diameter), located to the right of the response keys, provided general illumination throughout the experimental session. Mixed grain from a hopper could be made available through a rectangular opening located directly below the keys and approximately $10 \mathrm{~cm}$ above the chamber floor. A white light was illuminated over the grain hopper during food delivery. Each chamber was ventilated by an exhaust fan, and white noise was continously present to mask extraneous sounds. Programming, recording, and data collection were accomplished with a Texas Instruments Inc. $960 \mathrm{~A}$ computer and cumulative recorders (Ralph Gerbrands Co., Arlington, MA).

Discrimination Training. Initially, each pigeon was required to emit a single peck on one of two keys in order to obtain $4 \mathrm{~s}$ access to mixed grain. The appropriate key to obtain reinforcement was determined by the injection the pigeon received prior to the session, i.e., either pentobarbital (left key) or saline (right key). The number of responses required for grain delivery was gradually increased to 20 (fixedratio 20 ), with the added requirement that the responses occur in succession. Responses on the inappropriate key reset the fixed-ratio requirement on the appropriate key. Sessions ended after 32 deliveries of mixed grain or $1 \mathrm{~h}$, whichever occurred first.

Training sessions were usually conducted 6 days a week, Monday through Saturday. Each pigeon was injected IM 5 min prior to each session with either $5 \mathrm{mg} / \mathrm{kg}$ pentobarbital (10 mg/kg for bird P-890) or saline $(0.1 \mathrm{ml} / 100 \mathrm{~g})$. Pentobarbital and saline injections alternated from one session to the next.

Training continued until each pigeon met the criteria of emitting fewer than 40 key pecks before the first food delivery of the session and distributing at least $90 \%$ of the total session responses on the appropriate key. Each bird was required to meet these criteria for five consecutive sessions during which saline and pentobarbital injections alternated, and then for four consecutive sessions during which saline and pentobarbital were administered in a double alternation sequence (e.g., pentobarbital, pentobarbital, saline, saline).

Discrimination Testing. Once these criteria were met, test sessions were conducted with a range of doses of pentobarbital, including the training dose, and the pentobarbital vehicle (see below). Throughout a test session, 20 consecutive responses on either the pentobarbitalappropriate or saline-appropriate key resulted in food delivery; in all other respects test sessions were identical to training sessions.

In general, test sessions alternated during the week with training sessions. If during a training session an animal failed to meet the criteria, further testing was postponed until the animal met the training criteria on at least two consecutive training sessions.

Once a dose-response curve for pentobarbital had been established, the ability of a variety of drugs to occasion pentobarbitalappropriate responding was investigated. Test sessions for these drugs were conducted as described above, with 20 consecutive responses on either the pentobarbital-appropriate or salineappropriate key resulting in reinforcer delivery. Dose-response curves for each drug were determined in each of at least three pigeons. The order of the drugs tested and the dose sequences were unsystematic. Dose-effect curves for ethanol were determined twice in each of five pigeons with no more than 3 days separating the completion of the first and the start of the second determination.

Drugs. The drugs used in these experiments were sodium pentobarbital, sodium phenobarbital, sodium barbital, sodium methohexital, ketamine hydrochloride, morphine sulfate, calcium valproate, sodium phenytoin, sodium ethosuximide, ethanol $(95 \%)$, bemegride, and muscimol. Ethylketazocine methane sulfonate and cyclazocine were provided by W. Michne, Sterling-Winthrop Research Institute, Rensselaer, NY. Dextrorphan tartrate, dextromethorphan hydrobromide, and diazepam were gifts from Hoffmann-LaRoche, Inc., Nutley, NJ. Clobazam was provided by Hoechst-Roussel Pharmaceuticals, Inc., Somerville, NJ. Chlorpromazine hydrochloride was donated by Smith, Kline and French Labs, Philadelphia, PA. Baclofen [ $\beta$-(4-chlorophenyl)- $\gamma$-aminobutyric acid] was provided by CIBA Pharmaceutical Co., Summit, NJ. SKF-10,047 hydrochloride ( $N$-allyl-normetazocine) was supplied by A. Jacobson, NIH.

Cyclazocine and ethylketazocine were dissolved in sterile water to which a small amount of lactic acid was added; if needed, sodium hydroxide was used to adjust the $\mathrm{pH}$ of the solutions to above 4 . The vehicle for pentobarbital was a solution containing ethanol, propylene glycol, and sterile water, in a ratio of $1: 2: 7$. Diazepam and 
clobazam were dissolved in a solution containing $40 \%$ propylene glycol, $10 \%$ ethanol, $5 \%$ sodium benzoate and benzoic acid, $1.5 \%$ benzyl alcohol, and $43.5 \%$ sterile water. Baclofen was dissolved in sterile water to which sodium hydroxide was added; hydrochloric acid was used to adjust the $\mathrm{pH}$ of the solution to approximately 9 . Phenytoin was dissolved in a mixture of sterile water and sodium hydroxide such that the $\mathrm{pH}$ of the solution was approximately 12 . Morphine, chlorpromazine, dextromethorphan, dextrorphan, and ketamine were dissolved in $0.9 \%$ sterile saline; valproate, ethosuximide, methohexital, phenobarbital, barbital, bemegride, muscimol, and SKF-10,047 were dissolved in sterile water. Drug doses refer to the forms described above.

Injections of all drugs, except ethanol, were made into the breast muscle, usually in a volume of $1 \mathrm{ml} / \mathrm{kg}$. Pentobarbital, diazepam, ethylketazocine, ketamine, methohexital, saline, and pentobarbital vehicle were injected $5 \mathrm{~min}$ before the session. Ethanol $(10 \% \mathrm{w} / \mathrm{v}$, diluted in tap water) or tap water was administered by gavage to the opening of the proventriculus with a $15 \mathrm{~cm}$ stainless steel animal feeding tube, $20 \mathrm{~min}$ before the session. Doses of ethanol were varied by adjusting the volume of the intubation. When pentobarbital $(10 \mathrm{mg} / \mathrm{kg})$ was administered orally, each bird was intubated $20 \mathrm{~min}$ before the session with a $0.1 \%$ solution of pentobarbital or the pentobarbital vehicle, in a volume of $1 \mathrm{ml} / 100 \mathrm{~g}$. All other drugs were injected IM $10 \mathrm{~min}$ before the session. When bemegride was administered in combination with pentobarbital, an injection of bemegride or sterile water was made into the breast muscle on one side of the animal $10 \mathrm{~min}$ prior to the session, followed $5 \mathrm{~min}$ later by an injection of pentobarbital or vehicle into the breast muscle on the opposite side.

Data Analysis. The data for test sessions are presented as the average number of responses throughout the session that were emitted on the pentobarbital-appropriate key, expressed as a percentage of the total responses. The remaining responses were always made on the salineappropriate key. A test drug was considered to produce discriminative effects similar to the training dose of pentobarbital if $90 \%$ of the total session responses were emitted on the pentobarbitalappropriate key.

The overall rate of responding on the two keys was also recorded during each session. The average response rates after drug injections, expressed as a percentage of the saline control rates, provided a measure of behavioral effect of the drugs which was unrelated to the distribution of responses on the two keys.

\section{Results}

Each of the seven pigeons acquired the pentobarbitalsaline discrimination in 15 to 36 sessions (mean $\pm \mathrm{SE}$ $=24 \pm 3$ ). In each pigeon, pentobarbital produced a dose-related increase in the percentage of the total session responses that were made on the pentobarbitalappropriate key. The lowest dose of pentobarbital $(1.0 \mathrm{mg} / \mathrm{kg})$ resulted in responding similar to that produced by saline and vehicle injections (Fig. 1, upper panel). Following injections of the training dose and higher doses of pentobarbital $(5.0-17.8 \mathrm{mg} / \mathrm{kg})$, each of the birds responded almost exclusively on the drugappropriate key. Only one of seven birds (P-261) was able to respond after receiving a dose of $32 \mathrm{mg} / \mathrm{kg}$ pentobarbital.

Diazepam and clobazam, two benzodiazepines, and the barbiturates methohexital, phenobarbital, and bar-

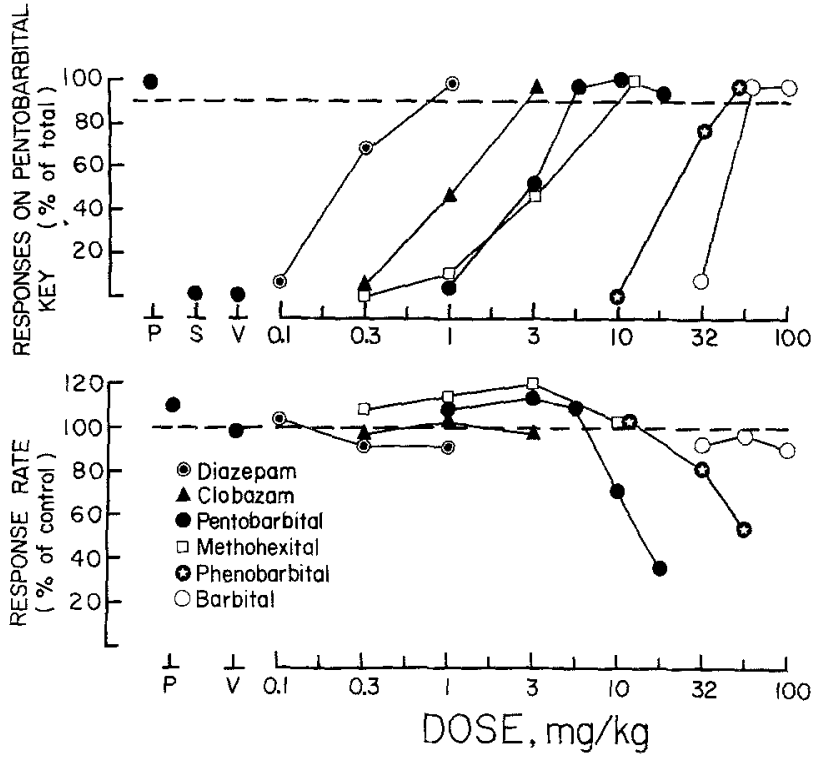

Fig. 1. Dose-response curves for the discriminative stimulus effects of pentobarbital and five other drugs that produced effects similar to those of pentobarbital (upper panel); and the effects of these drugs on the rate of responding (lower panel). The upper panel ordinate indicates the average number of responses emitted on the pentobarbital-appropriate key, expressed as a percentage of the total session responses. The lower panel ordinate indicates the average rate of responding after drug injections, expressed as percentage of the rates of responding on saline training sessions. The abscissae indicate the doses of the drugs, in $\mathrm{mg} / \mathrm{kg}$. Each point represents the mean of one observation in each of three animals $(N=3)$, except for pentobarbital where $N=7$. The effects of the training dose of pentobarbital and saline on response distribution for training sessions which preceded test sessions are indicated in the upper panel at $\mathbf{P}$ and $\mathrm{S}$, respectively. The effect of the training dose of pentobarbital on the rate of responding during these sessions is indicated at $P$ in the lower panel. The effects of tests with the pentobarbital vehicle are shown at $\mathrm{V}$

bital produced dose-related increases in responding on the pentobarbital-appropriate key that reached maxima above $90 \%$ of the total session responses (Fig. 1, upper panel). For each of these drugs, the doseresponse curves determined by averaging the performances of all the birds were almost identical to those of individual pigeons. Assigning pentobarbital a potency of 1 , the relative potencies for these drugs (considering the lowest dose necessary to produce $90 \%$ pentobarbital-appropriate responding) were diazepam, 5; clobazam, 1.6; pentobarbital, 1; methohexital, 0.5; phenobarbital, 0.1 ; and barbital, 0.1 .

The effects of these drugs on the rate of key-peck responding are shown in the lower panel of Fig. 1. Except for phenobarbital, each of these drugs produced more than $90 \%$ pentobarbital-appropriate responding at doses that had little or no effect on response rates (Fig. 1, lower panel).

Antagonism by Bemegride of the Discriminative Effects of Pentobarbital. Bemegride $(5.6-17.8 \mathrm{mg} / \mathrm{kg})$ shifted 


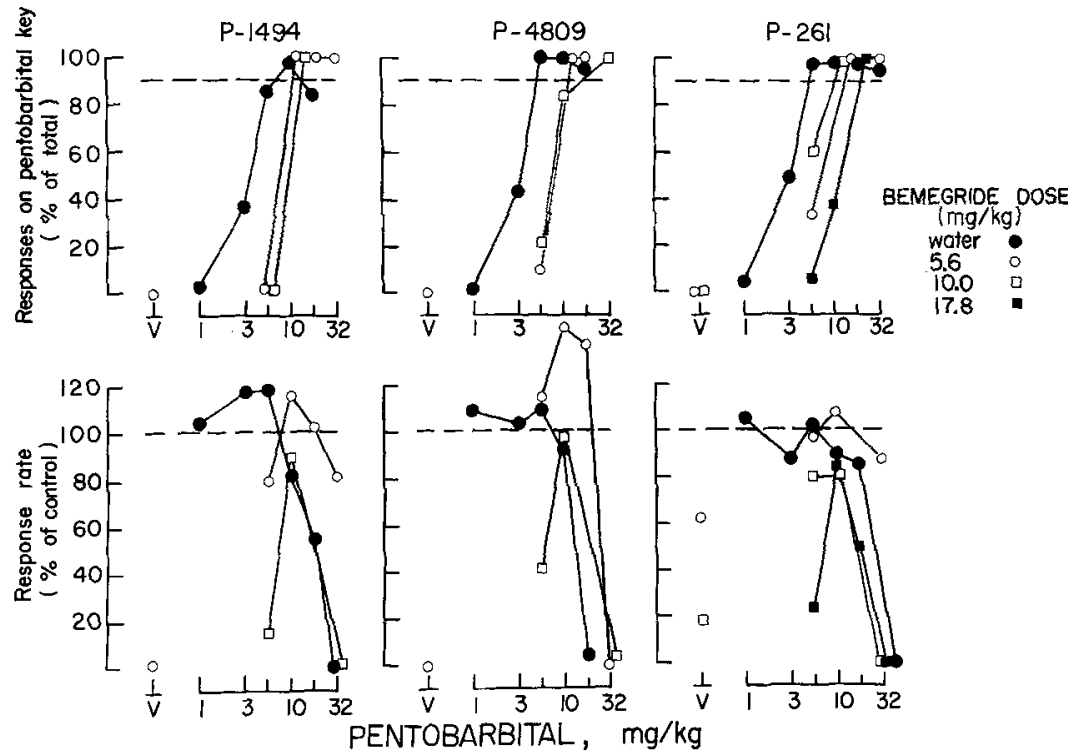

Fig. 2

Antagonism of the discriminative effects of pentobarbital by bemegride in individual animals. The upper panels show the effects of bemegride or sterile water administered in combination with increasing doses of pentobarbital on the number of responses emitted on the pentobarbital-appropriate key, expressed as a percentage of the total session responses. The lower panel ordinates indicate the rate of responding after injections of the drugs, expressed as a percentage of the rates of responding on saline training sessions. The abscissae indicate the dose of pentobarbital, in $\mathrm{mg} / \mathrm{kg}$. The effects of bemegride in combination with pentobarbital vehicle are shown at $\mathrm{V}$

Table 1. Drugs that failed to produce discriminative effects similar to those of pentobarbital

\begin{tabular}{|c|c|c|c|c|}
\hline \multirow{2}{*}{$\begin{array}{l}\text { Drug } \\
\text { (dose range tested, } \mathrm{mg} / \mathrm{kg} \text { ) }\end{array}$} & \multicolumn{3}{|c|}{ Maximum pentobarbital response } & \multirow{2}{*}{$\begin{array}{l}\text { Response rate, } \\
\text { highest dose tested } \\
\text { (\% of control) }\end{array}$} \\
\hline & $\begin{array}{l}\text { Dose } \\
(\mathrm{mg} / \mathrm{kg})\end{array}$ & $\begin{array}{l}\text { Responses on } \\
\text { pentobarbital key } \\
(\% \text { of total) }\end{array}$ & $\begin{array}{l}\text { Response rate } \\
(\% \text { of control })\end{array}$ & \\
\hline Morphine $(1.0-10)$ & 5.6 & $2^{\mathrm{a}}$ & 54 & 22 \\
\hline Ethylketazocine $(0.1-10)$ & 3.2 & 3 & 46 & 33 \\
\hline Cyclazocine $(0.3-3.2)$ & 3.2 & 6 & 3 & 3 \\
\hline SKF-10,047 $(1.0-17.8)$ & 10 & 11 & 20 & 12 \\
\hline Muscimol $(0.1-1.0)$ & 0.6 & 5 & 75 & 0 \\
\hline Baclofen $(3.2-32)$ & - & 0 & - & 0 \\
\hline Chlorpromazine $(10-100)$ & 56 & 11 & 19 & 1 \\
\hline Dextromethorphan $(3.2-17.8)$ & 10 & 2 & 37 & 30 \\
\hline Bemegride $(0.1-10)$ & 1.0 & 3 & 60 & 18 \\
\hline Valproate $(3.2-100)$ & 56 & 1 & 65 & 0 \\
\hline Phenytoin $(3.2-17.8)$ & 10 & 2 & 27 & 3 \\
\hline Ethosuximide $(10-100)$ & 56 & 2 & 45 & 33 \\
\hline Dextrorphan $(3.2-32)$ & 17.8 & 48 & 34 & 7 \\
\hline Ketamine $(0.3-32)$ & $32^{b}$ & 42 & 11 & 11 \\
\hline
\end{tabular}

a The entries are the average of single observations in three pigeons $(N=3)$, except for bemegride $(N=4)$, dextrorphan $(N=5)$, and ketamine $(N=5)$

b One of five birds did not respond after receiving $32 \mathrm{mg} / \mathrm{kg}$ ketamine

the dose-effect curve for the discriminative stimulus effects of pentobarbital 2-3-fold to the right (Fig. 2, upper panels). In each pigeon, $5.6 \mathrm{mg} / \mathrm{kg}$ and $10 \mathrm{mg} / \mathrm{kg}$ bemegride antagonized the discriminative effects of $5.0 \mathrm{mg} / \mathrm{kg}$ pentobarbital to about the same extent, and in one bird, P-261, $17.8 \mathrm{mg} / \mathrm{kg}$ bemegride was more effective as an antagonist than the lower doses. In contrast, the discriminative effects of higher doses of pentobarbital $(17.8-32 \mathrm{mg} / \mathrm{kg})$ were not affected by any tested dose of bemegride. Bemegride did, however, antagonize the response rate-suppressing effects of high doses of pentobarbital (Fig. 2, lower panels). The optimum dose of bemegride needed to reverse the rate suppression produced by $17.8-32 \mathrm{mg} / \mathrm{kg}$ pentobarbital was $5.6 \mathrm{mg} / \mathrm{kg}$. Both lower (not shown) and higher doses $(10.0-17.8 \mathrm{mg} / \mathrm{kg})$ of bemegride were less effective. Conversely, pentobarbital attenuated the suppression of responding produced by bemegride (Fig. 2, lower panels: note rate suppression produced by bemegride in combination with pentobarbital vehicle, indicated by points at $\mathrm{V}$ ).

Drugs that Failed to Produce Discriminative Effects Similar to Those of Pentobarbital. Table 1 lists drugs 

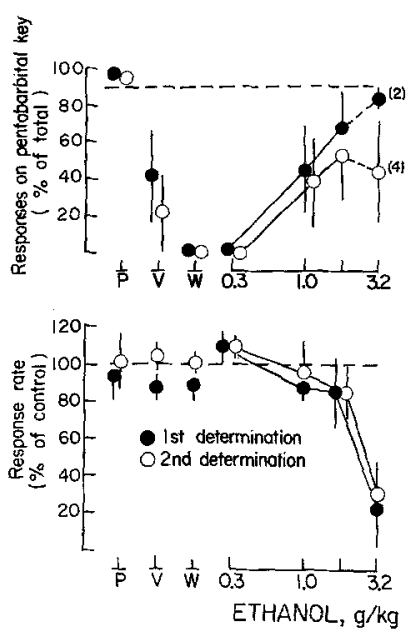

Fig. 3. Dose-response curves for the discriminative stimulus effects of ethanol (orally) in pigeons trained to discriminate IM pentobarbital from saline. Each point represents the mean of one observation in each of five animals, except where noted in parentheses. Brackets around each point indicate \pm 1 standard error of the mean. The points at $P$ show the effects of $10 \mathrm{mg} / \mathrm{kg}$ pentobarbital (orally); points at $\mathrm{V}$, the effects of pentobarbital vehicle (orally); and points at $\mathrm{W}$, the effects of tap water (orally). Refer to the caption of Fig. 1 for further details. Note that the intubated volume of $1 \mathrm{ml} / 100 \mathrm{~g}$ of the pentobarbital vehicle (see Materials and Methods) resulted in a dose of $1 \mathrm{~g} / \mathrm{kg}$ ethanol

that did not produce discriminative effects similar to those of pentobarbital. These included compounds from various pharmacological classes such as narcotics (morphine, ethylketazocine), narcotic antagonists (cyclazocine, SKF-10, 047), anticonvulsants (valproate, phenytoin, ethosuximide), antitussives (dextromethorphan, dextrorphan), and a variety of other drugs. Except for ketamine and dextrorphan, each of these compounds occasioned less than $11 \%$ pentobarbitalappropriate responding, up to and including doses that markedly reduced rates of responding. The most effective doses of dextrorphan $(17.8 \mathrm{mg} / \mathrm{kg})$ and ketamine $(32 \mathrm{mg} / \mathrm{kg})$ produced pentobarbital-appropriate responding that ranged in different birds from $0-88 \%$ and $7-94 \%$, respectively. In contrast to pentobarbital and the majority of drugs in Fig. 1, ketamine and dextrorphan produced pentobarbital-appropriate responding at doses that suppressed response rates (Table 1). Moreover, a dose of bemegride $(5.6 \mathrm{mg} / \mathrm{kg}$ ) that antagonized the discriminative and rate-decreasing effects of pentobarbital, had little or no effect on either the distribution of responses or response rate suppression in those birds in which dextrorphan and ketamine produced pentobarbital-appropriate behavior.

Ethanol. Dose-response curves for ethanol (orally) were determined twice in each of five pigeons and the average effect for the first and second determinations are shown in Fig. 3. When $10 \mathrm{mg} / \mathrm{kg}$ pentobarbital was adminis- tered orally, each of the five birds, on both determinations, responded almost exclusively on the pentobarbital-appropriate key. Intubations of tap water produced an average of less than $2 \%$ drugappropriate behavior, while the oral administration of the pentobarbital vehicle occasioned an average of $20-$ $40 \%$ pentobarbital-appropriate responding. Ethanol $(0.3-3.2 \mathrm{~g} / \mathrm{kg})$ produced a dose-related increase in pentobarbital-appropriate responding in most animals (four of five birds on the first determination; three of five on the second determination), although the maximum response to ethanol, in contrast to pentobarbital (10 $\mathrm{mg} / \mathrm{kg}$, orally), differed among birds. At a dose of ethanol at which all the birds were able to complete the session $(1.8 \mathrm{~g} / \mathrm{kg})$, individual birds emitted $3,78,78,86$, and $97 \%$ of the total session's responses on the pentobarbital-appropriate key on the first determination, and $0,0,80,87$, and $97 \%$ on the second determination. In general, a higher dose of ethanol, $3.2 \mathrm{~g} / \mathrm{kg}$, did not increase the percentage of drugappropriate responses in individual birds, although it completely abolished responding on four out of ten occasions.

\section{Discussion}

Pigeons trained to discriminate pentobarbital from saline generalized completely to two benzodiazepines, clobazam and diazepam, and to the barbiturates, methohexital, phenobarbital, and barbital. These results are consistent with findings in several other species in which pentobarbital discrimination has been studied, including rats (e.g., Barry 1974; Colpaert et al. 1976), gerbils (e.g., Jarbe 1976), and rhesus monkeys (Winger and Herling, unpublished observations). Moreover, the rank order of potency among these compounds is consistent across species, where such comparisons are available, despite differences in training and testing conditions. The order of potency of compounds that have been studied in more than one species is: diazepam $>$ clobazam $>$ pentobarbital $>$ phenobarbital $>$ barbital (Overton 1966; Colpaert et al. 1976; Jarbe 1976; Winger and Herling, unpublished observations).

The interaction between bemegride and pentobarbital in this experiment is also consistent with that reported in other species. In rats and gerbils, the combination of pentobarbital and bemegride produces saline-appropriate responding (Overton 1966; Krimmer 1974; Jarbe 1976). Similarly, in this experiment using pigeons, bemegride produced a small (2-3fold) but reliable shift to the right in the pentobarbital dose-response curve. Unlike the narcotic antagonist naltrexone, which is capable of antagonizing the discriminative effects of morphine at doses 300 times lower 
than those needed to suppress response rates (e.g., Valentino et al. 1980), bemegride reliably antagonized the discriminative effects of pentobarbital only at doses that when given alone markedly reduced rates of responding. In addition, pentobarbital and bemegride reversed the rate-decreasing effects of the other, suggesting a mutually antagonistic interaction (Fig. 2). A similar interaction between the behavioral effects of pentobarbital and bemegride has been reported in rats (e.g., Krimmer et al. 1978).

Pentobarbital and several benzodiazepines also effectively antagonize the discriminative effects of pentylenetetrazol, a convulsant with discriminative properties similar to those of bemegride (Shearman and Lal 1978, 1979). The order of potency of barbiturates and benzodiazepines in reversing the discriminative and seizure-inducing effects of pentylenetetrazol is well correlated with that of their discriminative effects (cf. Colpaert 1977; Shearman and Lal 1978, 1979). That the discriminative stimulus effects of drugs that generalize to pentobarbital may be intimately related to their ability to antagonize pentylenetetrazol is supported by our finding that phenytoin and ethosuximide, two anticonvulsants that are ineffective antagonists of the pentylenetetrazol cue (Shearman and Lal 1979), did not generalize to pentobarbital (Table 1). Moreover, phenytoin does not elevate the threshold for seizures induced by pentylenetetrazol (Goodman et al. 1946, 1953).

Although many GABA-mimetics are effective against various types of seizure activity (see Enna and Maggi 1979 for review) muscimol, a direct GABA agonist, valproate, a GABA-transaminase inhibitor, and baclofen, a structural analogue of GABA, did not induce pentobarbital-appropriate responding up to doses that completely abolished responding. In rats, GABAergic drugs such as $\gamma$-acetylenic GABA and $\gamma$ vinyl GABA (two irreversible GABA-transaminase inhibitors), do not antagonize the discriminative effects of pentylenetetrazol (Shearman and Lal 1979), nor do they prevent pentylenetetrazol-induced seizures (e.g., Myslobodsky et al. 1979). The finding that muscimol, valproate, and baclofen did not generalize to pentobarbital in the present experiment might predict that these drugs would also be ineffective antagonists of pentylenetetrazol.

A variety of drugs failed to produce discriminative stimulus effects similar to those of pentobarbital. Cyclazocine and SKF-10,047, mixed narcotic agonistantagonists in many preparations (e.g., Martin et al. 1976; Nemeth 1979), as well as chlorpromazine, dextromethorphan, and bemegride, failed to produce pentobarbital-appropriate responding. Similarly, morphine and ethylketazocine, narcotics with similar behavioral effects in the pigeon (Herling et al. 1980a), resulted in almost exclusive saline-key responding. Conversely, pentobarbital does not substitute for morphine in several species of animals trained to discriminate morphine from saline (Shannon and Holtzman, 1976; Schaefer and Holtzman 1977; Jarbe 1978; Herling et al. 1980a). Our results, however, are somewhat at odds with the finding reported by Leberer and Fowler (1977). Pigeons trained to discriminate three drug conditions - pentobarbital, $d$-amphetamine and saline - in a three-key discrimination situation, emitted more than $80 \%$ of their responses on the pentobarbital-appropriate key after being injected with $10 \mathrm{mg} / \mathrm{kg}$ morphine (Leberer and Fowler 1977). This unique and intriguing finding suggests a similarity between the discriminative effects of morphine and pentobarbital under these particular training conditions.

Of the various drugs listed in Table 1, only dextrorphan and ketamine produced effects sufficiently similar to those of pentobarbital that some birds responded on the pentobarbital key. The data reported here for ketamine are consistent with results in rats. Overton (1975) reported that neither ketamine nor phencyclidine is interchangeable with pentobarbital, although both compounds result in approximately $50 \%$ first-trial pentobarbital choices in a $\mathrm{T}$-maze. Similarly, under the conditions of the present experiment, ketamine, as well as dextrorphan, produced approximately $50 \%$ pentobarbital-appropriate responding. Interestingly, in the pigeon, ketamine and dextrorphan also produce similar discriminative stimulus effects (Herling et al. 1980b).

The relationship between the discriminative effects of ethanol and barbiturates has been the subject of considerable research (e.g., Overton 1966, 1977; Barry and Krimmer 1972; Barry 1974; York 1978), and models that consider the differential behavioral pharmacology of these drugs and differences in training conditions have been proposed to account for conflicting findings (e.g., Barry and Krimmer 1977, 1978). In the present experiment, alcohol produced more than $78 \%$ pentobarbital-appropriate responding in four of five birds on the first determination, and in three of five birds on the second determination. Why ethanol produced variable effects under the conditions of the present experiment is not clear. A similar finding, however, was reported in rats trained to discriminate pentobarbital $(10 \mathrm{mg} / \mathrm{kg}$, IP) from saline in a foodreinforced two-lever choice procedure (Krimmer and Barry 1973). In pigeons, as in rats, the discriminative effects of ethanol appear sufficiently similar to those of pentobarbital that ethanol produces pentobarbitalappropriate responding in some subjects. As in the rat, the dissimilarity of the two drugs might be accentuated in the pigeon under different training conditions (e.g., 
Overton 1977; Barry and Krimmer 1978). Nevertheless, the results of the present study suggest that the pattern and degree of generalization of a variety of drugs to pentobarbital in the pigeon is similar to that observed in several mammalian species including rats, gerbils, and rhesus monkeys (e.g., Colpaert et al. 1976; Jarbe 1976; Winger and Herling, unpublished observations).

Acknowledgements. This research was supported by USPHS grant DA 02230 (to G.D. Winger). R. J. Valentino was supported as a predoctoral fellow by NIGMS grant GM 00198. The authors would like to thank Kari L. George for her invaluable assistance in conducting this experiment; James H. Woods for his guidance and helpful suggestions throughout the course of the study; Michelle $\mathrm{R}$. Hacker for her assistance in preparing the manuscript; and Alice $M$. Young for her helpful comments and editorial assistance on an earlier draft of this paper.

\section{References}

Barry H, III (1974) Classification of drugs according to their discriminable effects in rats. Fed Proc 33:1814-1824

Barry H, III, Krimmer EC (1972) Pentobarbital effects perceived by rats as resembling several other depressants but not alcohol. Proc 80th Am Psychol Assoc 7:849-850

Barry H, III, Krimmer EC (1977) Discriminable stimuli produced by alcohol and other CNS depressants. In: Lal H (ed) Discriminative stimulus properties of drugs. Plenum Press, New York, p 73

Barry H, III, Krimmer EC (1978) Similarities and differences in discriminative stimulus effects of chlordiazepoxide, pentobarbital, ethanol, and other sedatives. In: Colpaert FC, Rosecrans JA (eds) Stimulus properties of drugs: Ten years of progress. Elsevier/North Holland Biomedical Press, Amsterdam, p 31

Colpaert FC (1977) Discriminative stimulus properties of benzodiazepines and barbiturates. In: Lal H (ed) Discriminative stimulus properties of drugs. Plenum Press, New York, p 93

Colpaert FC, Desmedt LKC, Janssen PAJ (1976) Discriminative stimulus properties of benzodiazepines, barbiturates, and pharmacologically related drugs; relation to some intrinsic and anticonvulsant effects. Eur J Pharmacol 37:113-123

Enna SJ, Maggi A (1979) Biochemical pharmacology of GABAergic agonists. Life Sci 24:1727-1738

Ferster CB, Skinner BF (1957) Schedules of reinforcement. Appleton-Century-Crofts, New York, p 14

Gilbert PE, Martin WR (1976) The effects of morphine- and nalorphine-like drugs in the nondependent, morphinedependent and cyclazocine-dependent chronic spinal dog. J Pharmacol Exp Ther 198:66-82

Goodman LS, Grewal MS, Brown WC, Swinyard EA (1953) Comparison of maximal seizures evoked by pentylenetetrazol (Metrazol) and electroshock in mice, and their modification by anticonvulsants. J Pharmacol Exp Ther 108:168-176

Goodman LS, Toman JEP, Swinyard EA (1946) The anticonvulsant properties of Tridione. Am J Med 1:213-228

Hein DW, Herling S, Young AM, Valentino RJ, Woods JH (1980) Qualitative differences between the discriminative stimulus characteristics produced by ethylketazocine in the rhesus monkey and the pigeon. Fed Proc 39:995

Herling S, Coale EH, Jr, Valentino RJ, Hein DW, Woods JH (1980a) Narcotic discrimination in pigeons. J Pharmacol Exp Ther 214: $139-146$
Herling S, Winger GD, Coale EH, Hein DW, Woods JH (1980b) Similarity of the discriminative stimulus effects of dextrorphan, ketamine, and cyclazocine in the pigeon. Fed Proc 39:994

Holtzman SG, Shannon HE, Schaefer GJ (1977) Discriminative properties of narcotic antagonists. In: Lal H (ed) Discriminative stimulus properties of drugs. Plenum Press, New York, p 47

Jarbe TUC (1976) Characteristics of pentobarbital discrimination in the gerbil: Transfer and antagonism. Psychopharmacology $49: 33-40$

Jarbe TUC (1978) Discriminative effects of morphine in the pigeon. Pharmacol Biochem Behav 9:411-416

Jarbe TUC, Ohlin GC (1979) Discriminative effects of combinations of $A^{9}$-tetrahydrocannabinol and pentobarbital in pigeons. Psychopharmacology 63:233-239

Johansson JO, Jarbe TUC (1975) Antagonism of pentobarbital induced discrimination in the gerbil. Psychopharmacologia $41: 225-228$

Krimmer EC (1974) Drugs as discriminative stimuli. Dissertation Abstr Internat 35:4572-B

Krimmer EC, Barry H, III (1973) Differential stimulus characteristics of alcohol and pentobarbital in rats. Proc Am Psychol Assoc $8: 1005-1006$

Krimmer EC, Barry H, III (1979) Pentobarbital and chlordiazepoxide differentiated from each other and from nondrug. Comm in Psychopharmacol 3:93-99

Krimmer EC, Barry H, III, Coltrin D (1978) Antagonism of pentobarbital discriminative stimulus by bemegride in immobilized rats. In: Colpaert FC, Rosecrans JA (ed) Stimulus properties of drugs: Ten years of progress. Elsevier/North Holland Biomedical Press, Amsterdam, p 167

Lebeter MR, Fowler SC (1977) Drug discrimination and generalization in pigeons. Pharmacol Biochem Behav 7:483-486

Martin WR, Eades CG, Thompson JA, Huppler RE, Gilbert PE (1976) The effects of morphine- and nalorphine-like drugs in the non-dependent and morphine-dependent chronic spinal dog. J Pharmacol Exp Ther 197:517-532

Myslobodsky MS, Ackermann RF, Engel J, Jr (1979) Effects of $\gamma$ acetylenic GABA and $\gamma$-vinyl GABA on metrazol-activated, and kindled seizures. Pharmacol Biochem Behav 11:265-271

Nemeth MA (1979) Benzomorphan drugs: effects on operant behavior and antagonism by naloxone. Paper presented at the American Psychological Association. New York, NY

Overton DA (1966) State-dependent learning produced by depressant and atropine-like drugs. Psychopharmacologia 10:6-31

Overton DA (1975) A comparison of the discriminable CNS effects of ketamine, phencyclidine, and pentobarbital. Arch Int Pharmacodyn Ther 215:180-189

Overton DA (1977) Comparison of ethanol, pentobarbital, and phenobarbital using drugs vs. drug discrimination training. Psychopharmacology 53:195-199

Schaefer GJ, Holtzman SG (1977) Discriminative effects of morphine in the squirrel monkey. J Pharmacol Exp Ther 201:67-75

Schaefer GJ, Holtzman SG (1978) Dicriminative effects of cyclazocine in the squirrel monkey. J Pharmacol Exp Ther 205:291 301

Shannon HE, Holtzman SG (1976) Evaluation of the discriminative effects of morphine in the rat. J Pharmacol Exp Ther 198:54-65

Shearman $G$, Lal $H$ (1978) Discriminative stimulus properties of pentylenetetrazol in the rat. In: Colpaert FC, Rosecrans JA (eds) Stimulus properties of drugs: Ten years of Progress. Elsevier/North Holland Biomedical Press, Ansterdam, p 181

Shearman G, Lal H (1979) Discriminative stimulus properties of picrotoxin, bemegride and pentylenetetrazol: A possible relationship between an anxiogenic action and pentylenetetrazol discriminative stimulus. Fed Proc 38:256

Trost JG, Ferraro DP (1974) Discrimination and generalization of drug stimuli in monkeys. In: Singh JM, Lal H (eds) Drug 
addiction, vol 3: Neurobiology and influences on behavior, Stratton, New York, p 223

Valentino RJ, Herling S, Woods JH, Medzihradsky F, Merz H (1980) Comparison between narcotic antagonists and their quaternary derivatives. Fed Proc 39:760

Witkin JM, Carter RB, Dykstra LA (1980) Discriminative stimulus properties of $d$-amphetamine-pentobarbital combinations. Psychopharmacology $68: 269-276$

Woods JH, Herling S, Valentino RJ, Hein DW, Coale EH (1979) Narcotic drug discriminations by thesus monkeys and pigeons.
In: Harris LS (ed) Problems of drug dependence 1979: Proceedings of the 41st Annual Scientific Meeting, The Committee on Problems of Drug Dependence, Inc. NIDA Research Monograph 27, US Govt Printing Office, Washington, p 128

York JL (1978) A comparison of the discriminative stimulus effects of ethanol, barbital, and phenobarbital in rats. Psychopharmacology 60:19-23

Received December 18, 1979; Final version May 14, 1980 